\title{
Contralateral recurrent Phyllodes tumor of the vulva in a teenager
}

\author{
G.A. Polaquini1, J. Minari Bozko², C.L. Minari3,4, A. Estremadoiro \\ Vargas $^{3}$, J.E. Jung 5 , R. Bernardini de Lima ${ }^{5}$, J.C. Linhares ${ }^{3,4}$, A. \\ Tsunoda 3,4 . \\ ${ }^{1}$ Hospital Erasto Gaertner, Cirurgia Oncologica, Curitiba, Brazil. - polaquiniguilherme@gmail.com \\ 2Universidade de Riberão Preto, Faculdade de Medicina, Riberão Preto, Brazil. \\ ${ }^{3}$ Hospital Erasto Gaertner, Ginecologia oncologica, Curitiba, Brazil. \\ ${ }^{4}$ Instituto de Oncologia do Paraná, Ginecologia Oncologica, Curitiba, Brazil. \\ ${ }^{5}$ Hospital Erasto Gaertner, Patologia, Curitiba, Brazil.
}

Phyllodes tumor of the vulva is a rare condition, potentially arising from extra-mammary glands or mammary-like tissue, with less than 20 cases described in the literature. Patients from 17yo to 69yo usually present a painless tumor, with no other symptoms. Surgical complete removal is the current mainstain therapy. This report describes the diagnostic and therapeutic management of a Phyllodes tumor of the vulva occuring in a 15 year old female.

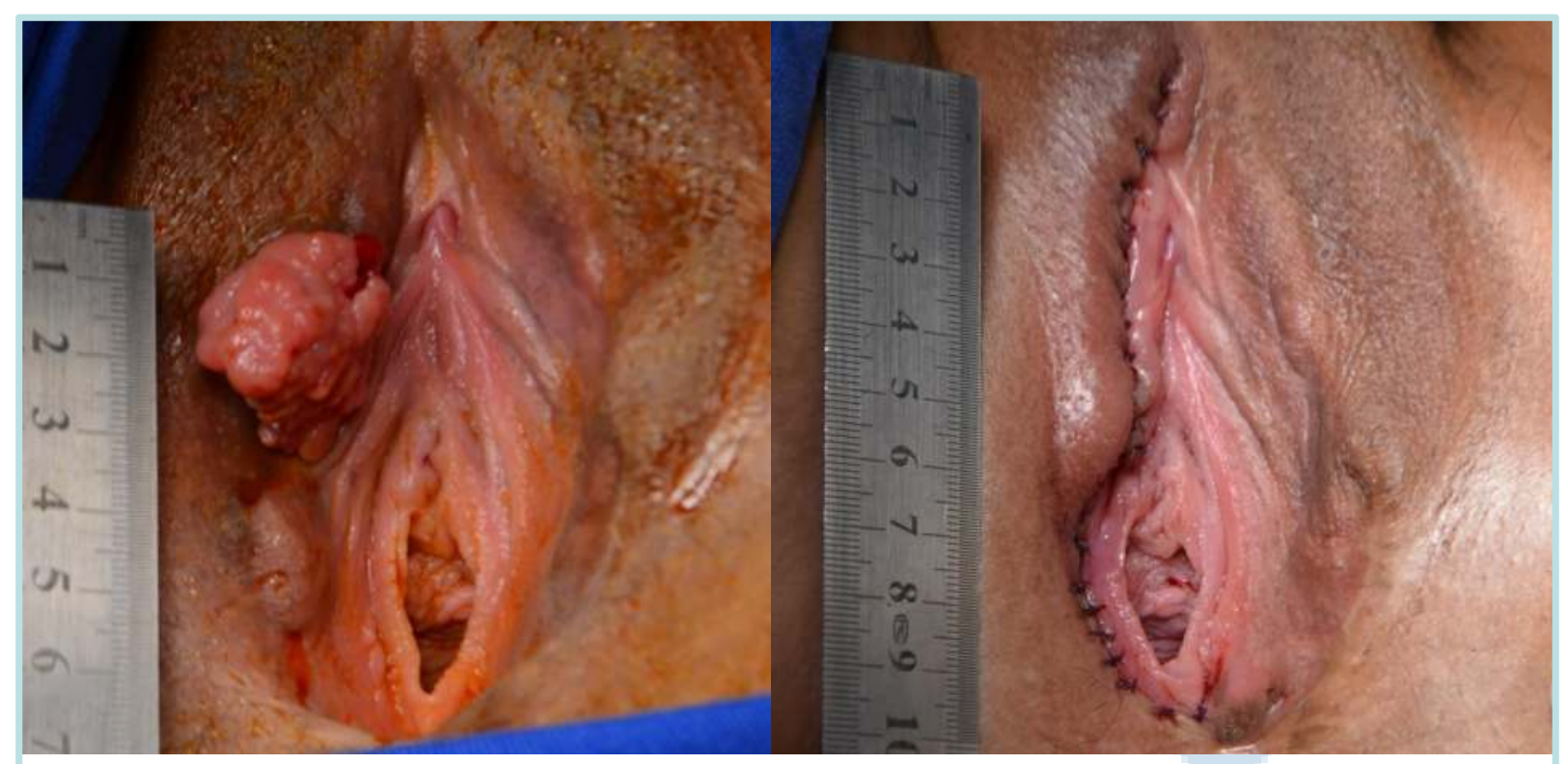

Fig.1 - Tumor and immediate surgical results

The patient presented a pedunculated vulvar mass on the left labia majora, with $8 \mathrm{~cm}$ in the largest diameter. CT scans suggested a localized non invasive tumor. A margin free local resection was performed. Pathology report was conclusive for a Phyllodes tumor (Fig.2a), with positive estrogen and progesterone receptors (Fig. $\mathbf{2 b}$ and $\mathbf{2 c}$ ), cytokeratin AE1/AE3 (Fig. 2d), and alpha smooth-muscle actin. Ki-67 index was $1 \%$. Two years later, she recurred in the contralateral labia majora, with two pedunculated lesions $(2 \mathrm{~cm}$ and $1,5 \mathrm{~cm})$. A surgical resection was proposed, with perioperative frozen-section analysis of the margins (Fig.1).

Final pathology reports revealed a new diagnosis of Phyllodes tumor of the vulva, with free margins (Fig.3)

There was a partial surgical site dehiscence, successfully managed conservatively. The patient is free of disease 8 months after last surgical resection.

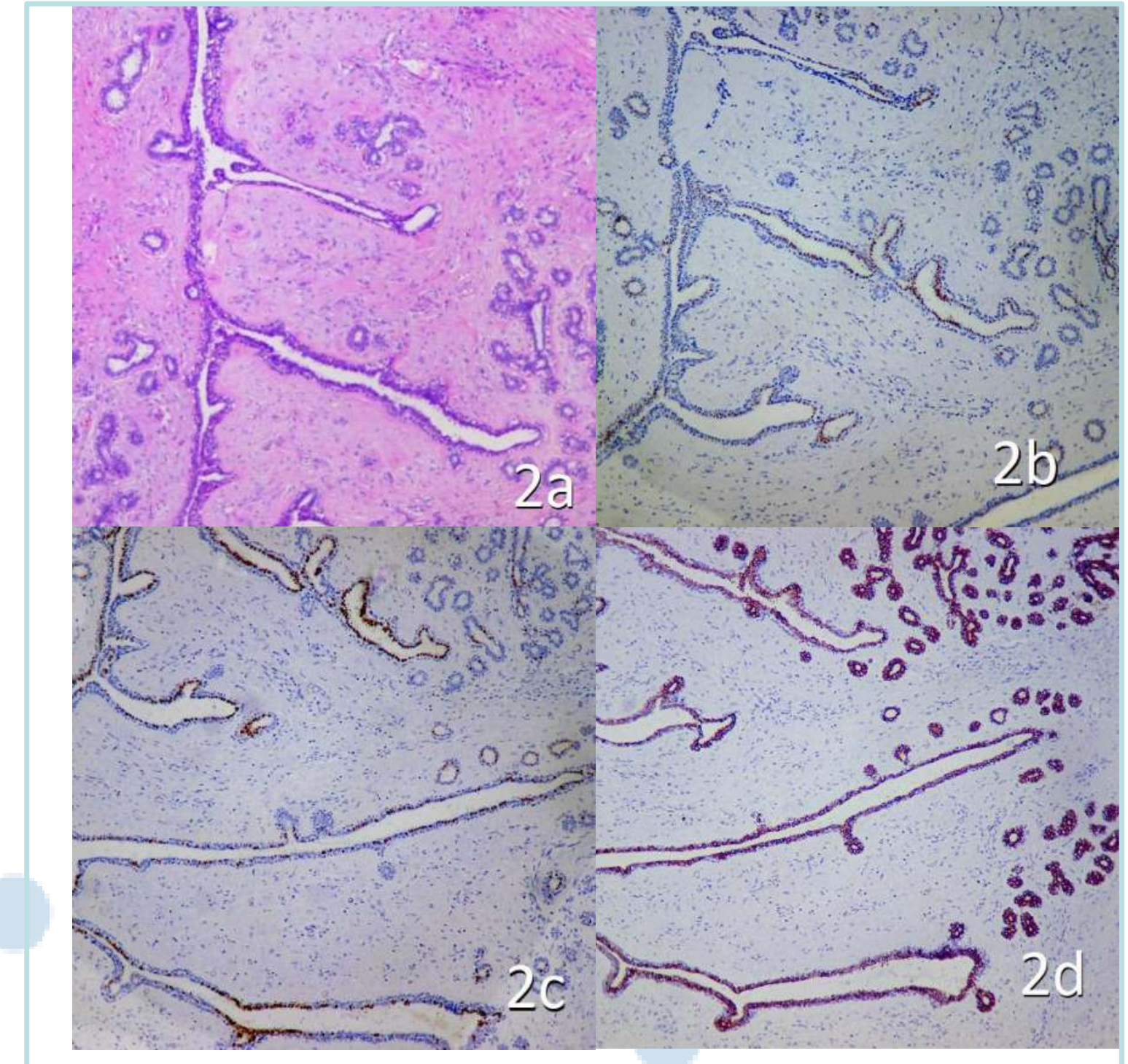

Fig.2 - Microscopy showing immunohistochemical stains used for diaqnosis

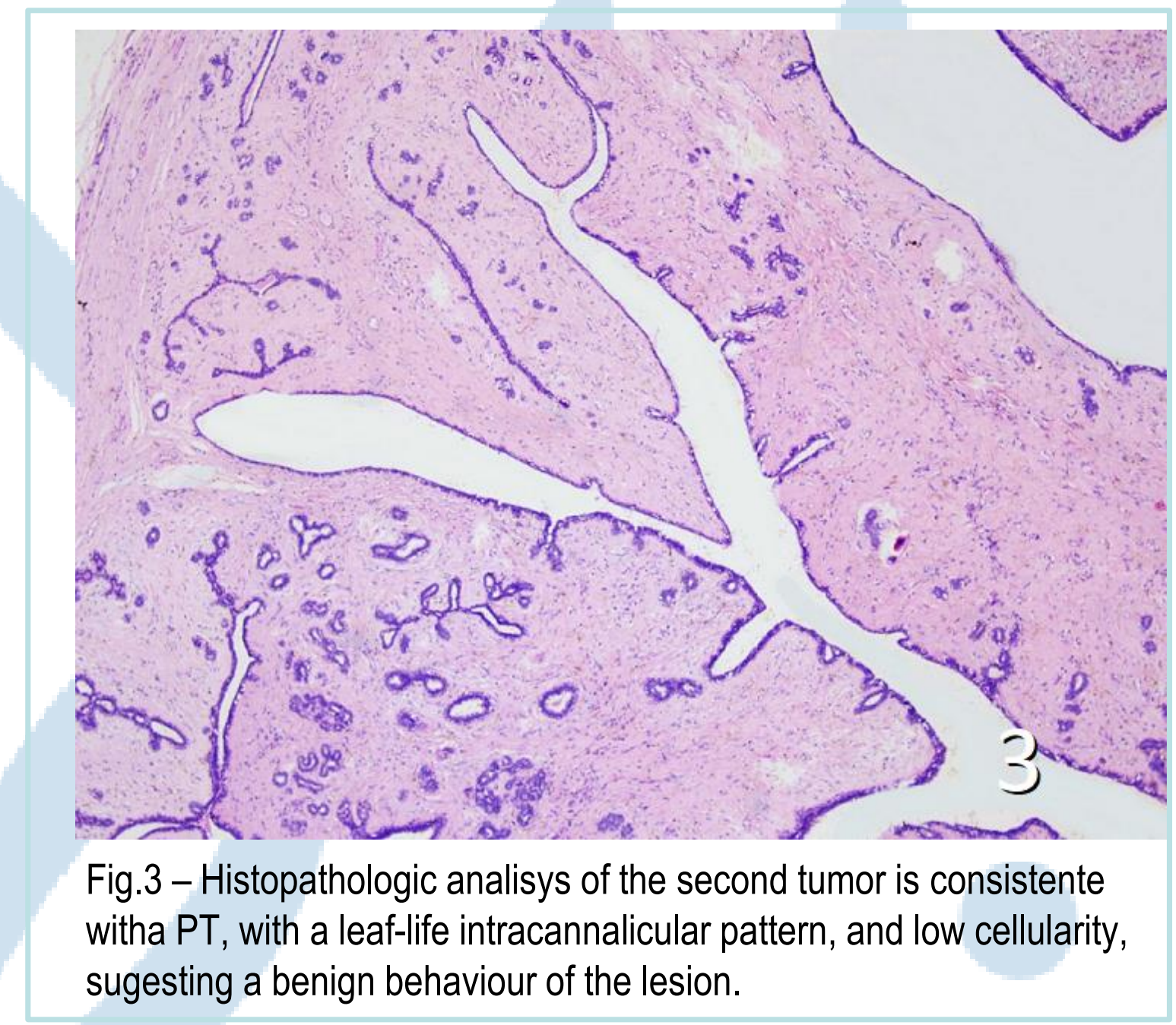

Conclusion: In this case report, an extremelly rare condition was diagnosed in a very young patient, with a contralateral recurrence, unusual for this type of tumor. Management was succesfull, with free margins local resections. 